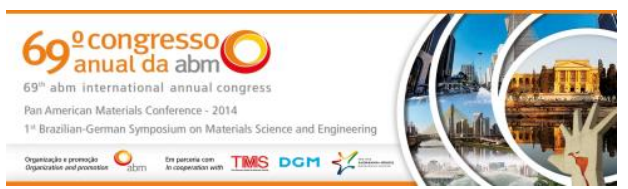

Tema: Tratamento térmico

\title{
DESENVOLVIMENTO DE AÇO LAMINADO A FRIO DE QUALIDADE COMERCIAL COM BOA CONFORMABILIDADE VIA RECOZIMENTO EM CAIXA PARA O MERCADO DE DISTRIBUIÇÃO*
}

\author{
Rafael Masulck Santos ${ }^{1}$ \\ Alexandre Pimentel Sampaio² \\ Fernando Generoso Neiva Ferreira ${ }^{3}$ \\ Nilton Vieira Larcher ${ }^{4}$
}

\section{Resumo}

A utilização de aços de baixo custo sempre foi uma tendência e ainda é hoje e em um mercado crescentemente globalizado. Este trabalho descreve o desenvolvimento de uma nova especificação de aço laminado a frio de qualidade comercial, de baixo custo de produção e boa conformabilidade, produzida na unidade de Volta Redonda da Companhia Siderúrgica Nacional (CSN) com o intuito de aumentar sua participação no segmento de mercado de Distribuição. Essa nova especificação, produzida via recozimento em Caixa (FRCX) em escala industrial, oferece aos clientes finais possibilidades múltiplas aplicações. Esse desenvolvimento, com abordagem multidisciplinar, é focado nos resultados de redução do custo de produção, satisfação dos clientes e a conquista de novos mercados.

Palavras-chave: Tratamento térmico industrial; Caixa; Segmento de Distribuição; Conformabilidade

\section{DEVELOPMENT OF COMMERCIAL QUALITY COLD ROLLED STEEL SHEET VIA BATCH ANNEALING TO THE SERVICE CENTER MARKET}

\begin{abstract}
Low cost commercial quality steel has always been a major trend and it is still today in a growing global market. The present work depicts the development of a new commercial quality specification for cold-rolled steel sheet, which has low production cost and good formability, produced at Volta Redonda works of Companhia Siderúrgica Nacional (CSN), aiming market share increase on Service Centers. The new specification, produced via industrial batch annealing, let available diverse applications to the end customers. This development, with multidisciplinary approach, is focused on production cost reduction, customer's satisfaction and reaching new market share.
\end{abstract}

Keywords: Industrial annealing; Batch annealing; Service center market; Formability.

Eng. Metalurgista, Companhia Siderúrgica Nacional, Volta Redonda, RJ, Brasil.

Eng. Metalurgista, M.Sc., Companhia Siderúrgica Nacional, Volta Redonda, RJ, Brasil.

Eng. Metalurgista, Companhia Siderúrgica Nacional, Volta Redonda, RJ, Brasil.

Metalurgia e Ciência dos Materiais, D.C., Companhia Siderúrgica Nacional, Volta Redonda, RJ, Brasil

\footnotetext{
* Contribuição técnica ao 69ำ Congresso Anual da ABM - Internacional e ao 14ํㅡㄹ ENEMET - Encontro Nacional de Estudantes de Engenharia Metalúrgica, de Materiais e de Minas, 21 a 25 de julho de 2014, São Paulo, SP, Brasil.
} 


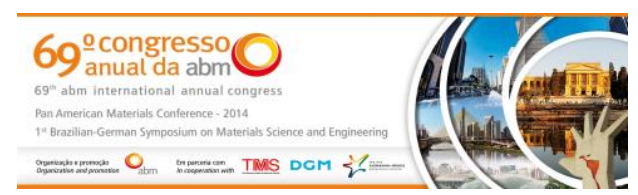

\section{INTRODUÇÃO}

A utilização de aços de baixo custo é hoje e sempre foi uma tendência em um mercado crescentemente globalizado. As especificações mais simples, que se caracterizam por uma quantidade menor de garantias de fornecimento por norma, vêm sendo utilizadas em aplicações cada vez variadas, assim expandindo seu espectro de usos. Esta é uma estratégia bastante utilizada no segmento da Distribuição, que tem forte participação de Centros de Serviços, para redução do custo da matéria-prima e maximizar suas margens na prestação de seus serviços. As usinas produtoras de aço vêm se adaptando a essa crescente demanda para se manterem a altura das necessidades de seus clientes e das características das aplicações desse mercado sempre em transformação.

O presente trabalho descreve o desenvolvimento em escala industrial de uma nova especificação de produto laminado a frio, que tem como focos baixo custo de produção e a necessidade de obter boa conformabilidade, características estas essenciais para o aumento da fatia de mercado no segmento de Distribuição.

Essa nova especificação tem como um de seus principais diferenciais, a utilização obrigatória do fluxo de produção via forno de recozimento em caixa (FRCX) que, a partir da otimização de seu ciclo térmico favoreceu atingir aos objetivos do projeto.

A utilização do FRCX foi possível graças ao aumento de sua capacidade produtiva, resultado de outro trabalho recente de grande impacto [1]. Além disso, foram definidas regras específicas de formação de carga, com o objetivo de se obter características mecânicas e metalúrgicas necessárias para a conquista de novos mercados. Outro resultado da entrada em produção em escala industrial dessa nova especificação nos FRCX da CSN foi a redução do custo de todos os produtos desta rota.

Este trabalho é fruto da integração multidisciplinar (produção, técnica, comercial etc.) do desenvolvimento de produtos na CSN visando objetivos comuns de conquista de novos mercados, redução do custo de produção e satisfação do cliente.

Do ponto de vista fenomenológico, a base do presente trabalho são os processos de difusão no estado sólido [2], termicamente ativados, que ocorrem no aço. As cinéticas de recuperação, recristalização e crescimento de grãos [3], regidas pela difusão de interfaces móveis que solubilizam e redistribuem os átomos em seus caminhos, são fundamentais para a formação um novo grão, isento de deformação, ou para o consumo de um grão com pequeno número de vértices [4]. Embora em uma descrição clássica monocristalina, esses processos sejam sequenciais, para um sólido policristalino a componente de energia interfacial, local em cada cristal, acaba por eliminar os contornos exatos de cada domínio de processo. Assim, causando uma mistura/simultaneidade na ordem dos eventos em todo o material, neste caso, uma bobina de aço com peso médio de $20 \mathrm{t}$. Esses processos se dão juntamente com a precipitação de nitreto de alumínio (AIN), que ancora contornos em planos e direções específicas, durante o processo de recozimento em caixa para viabilizar uma textura anisotrópica e mais adequada a determinadas solicitações de deformação. Além disso, embora seja objetivada uma microestrutura oriunda da laminação a quente com cementita mais robusta nos contornos de grão da ferrita, quando se dá a formação de finos carbonetos durante o resfriamento da laminação a quente, há a possibilidade da redistribuição de $C$ ainda durante a etapa de reaquecimento do ciclo térmico [5]. De fato, o presente trabalho é focado em variáveis industriais e não apresentará evidências microestruturais.

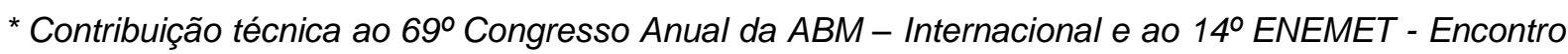
Nacional de Estudantes de Engenharia Metalúrgica, de Materiais e de Minas, 21 a 25 de julho de 2014, São Paulo, SP, Brasil.
} 


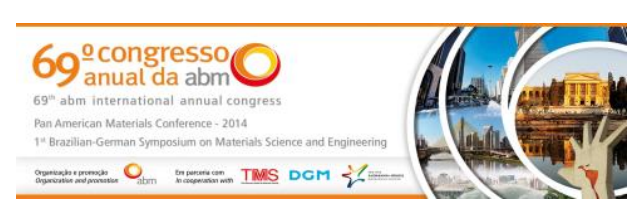

\section{MATERIAIS E MÉTODOS}

\subsection{Composição Química}

A composição química de referência utilizada foi a de produtos de qualidade comercial (QC) similar ao da NBR 6658 [6], ou seja um aço C-Mn.

\subsection{Propriedades Mecânicas}

Como as especificações similares a QC não exibem requisitos de propriedades mecânicas, uma referência para o limite inferior de conformabilidade foi utilizada. Daí, a amostragem realizada de produtos com a especificação EEP da NBR 5915 [7] (Tabela 1).

As amostras de produto laminado a frio selecionadas para testes comparativos foram obtidas em duas espessuras produzidas via linha de recozimento contínuo de chapas (LRCC) e via forno de recozimento em caixa (FRCX) (Tabela 1).

\subsection{1 ensaio Erichsen [8]}

O ensaio Erichsen foi utilizado como medida de conformabilidade. O resultado obtido é a profundidade da conformação obtida (IE). Quanto maior IE, maior a capacidade do produto de suportar deformação, dependendo do critério, antes de romper ou apresentar uma trinca.

A descrição completa do ensaio é feita na norma DIN EN ISO 20482 [8]. De forma resumida, a chapa é inicialmente fixada entre a matriz e o anel de sujeição com carga de pré-estabelecida. O punção tem formato esférico. Para a realização do ensaio a extremidade do punção é lubrificada, normalmente com uma graxa grafitada termo-resistente. O ensaio submete a chapa plana a um estiramento biaxial, e o resultado obtido é influenciado pela espessura da chapa.

Cada amostra (Tabela 1) foi preparada em corpos-de prova (tiras). Cada CP foi ensaiado em 3 diferentes posições (Borda, Centro e Borda1), Figura 1.

\begin{tabular}{|c|c|c|}
\hline ESPESSURA & AMOSTRAS & ESPECIFICAÇÃO \\
\hline \multirow{4}{*}{$0,6 \mathrm{~mm}$} & $\begin{array}{c}\text { LOTE "A" - início } \\
\text { LOTE "A" -fim }\end{array}$ & QC (via LRCC) \\
\hline & $\begin{array}{c}\text { LOTE "B" - início } \\
\text { LOTE "B" - fim } \\
\end{array}$ & QC (via FRCX) \\
\hline & $\begin{array}{l}\text { LOTE "C" - início } \\
\text { LOTE "C" - fim }\end{array}$ & Nova especificação (via FRCX) \\
\hline & $\begin{array}{c}\text { LOTE "D" - início } \\
\text { LOTE "D" - fim }\end{array}$ & NBR 5915 EEP (via FRCX) \\
\hline \multirow{4}{*}{$1,2 \mathrm{~mm}$} & $\frac{\text { LOTE "A" -início }}{\text { LOTE "A" -fim }}$ & QC (via LRCC) \\
\hline & $\begin{array}{c}\text { LOTE "B" - início } \\
\text { LOTE "B" - fim }\end{array}$ & QC (via FRCX) \\
\hline & $\begin{array}{c}\text { LOTE "C" - início } \\
\text { LOTE "C" - fim }\end{array}$ & Nova especificação (via FRCX) \\
\hline & $\begin{array}{c}\text { LOTE “D" - início } \\
\text { LOTE "D" - fim }\end{array}$ & NBR 5915 EEP (via FRCX) \\
\hline
\end{tabular}

\footnotetext{
* Contribuição técnica ao $69^{\circ}$ Congresso Anual da ABM - Internacional e ao 14ํㅡㄹ ENEMET - Encontro Nacional de Estudantes de Engenharia Metalúrgica, de Materiais e de Minas, 21 a 25 de julho de 2014, São Paulo, SP, Brasil.
} 

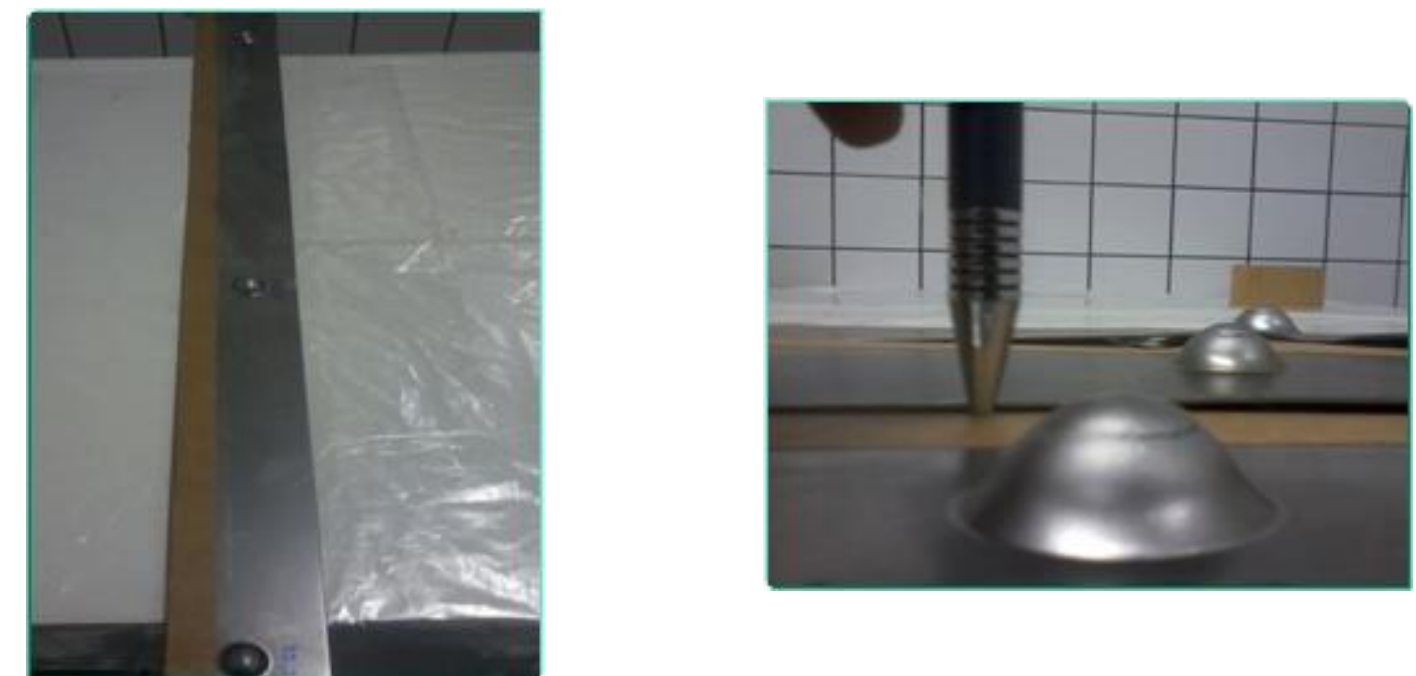

Figura 1. Corpo-de-prova para ensaio de conformabilidade. (a) Corpo-de-prova (tira); (b) Detalhe da calota produzida após ensaio.

\subsection{Processamento Industrial}

\subsubsection{Fluxograma de produção}

A partir da etapa de refino do aço, o fluxo de produção contou com processamento na aciaria LD, lingotamento contínuo de placas, laminação a quente (com prévio reaquecimento de placa), decapagem contínua, laminação a frio, forno de recozimento em caixa, laminador de encruamento (Figura 2).

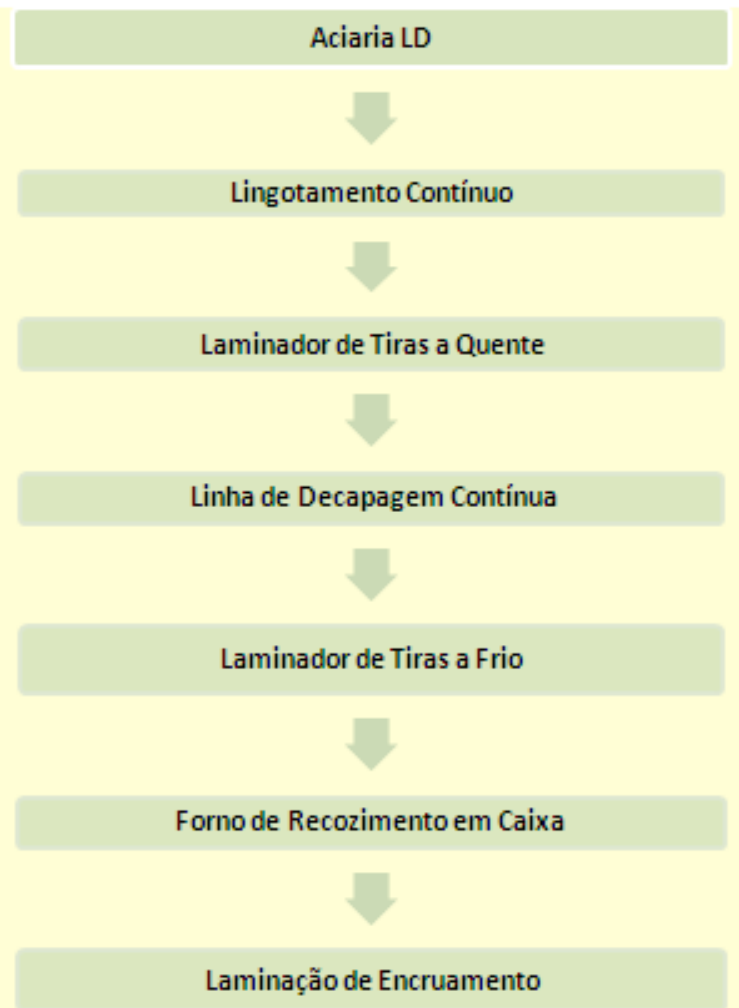

Figura 2. Fluxograma de produção da nova especificação de produto laminado a frio.

\footnotetext{
* Contribuição técnica ao 69ํ Congresso Anual da ABM - Internacional e ao 14ํㅡㄹ ENEMET - Encontro Nacional de Estudantes de Engenharia Metalúrgica, de Materiais e de Minas, 21 a 25 de julho de 2014, São Paulo, SP, Brasil.
} 


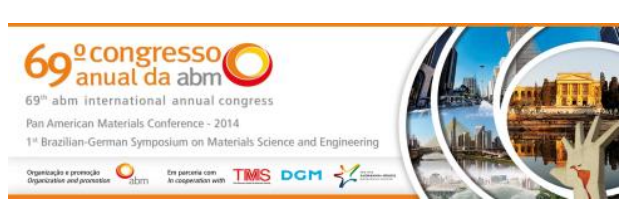

\subsubsection{Regra de fluxo e formação de carga}

Para garantir que o produto sempre fosse submetido ao ciclo térmico desenvolvido, definiu-se como obrigatoriedade o fluxo de produção via FRCX e como regra de agrupamento de carga. Essa ação foi importante, já que diversos materiais laminados a frio, não têm obrigatoriedade de rota, podendo ser tratados termicamente tanto em recozimento em caixa, quanto em continuo devido a falta de exigência de características mecânicas e metalúrgicas em especificações de QC.

Essa ação, também garantiu que no processo de recozimento em caixa, sempre seja aplicado o ciclo desenvolvido evitando misturas indesejadas na composição de carga.

\section{RESULTADOS}

\subsection{Processamento no Forno de Recozimento em Caixa}

\subsubsection{Etapa de aquecimento}

Uma redução de $17 \%$ foi realizada na taxa de aquecimento. A nova condição de aquecimento é representada pela linha verde na Figura 3. A condição anterior é representada pela linha vermelha na mesma figura.

\subsubsection{Etapa de encharque}

Um aumento de $10{ }^{\circ} \mathrm{C}$ foi realizado na temperatura de encharque. A nova condição é indicada pela linha verde na Figura 4. A condição anterior é representada pela linha vermelha na mesma figura.

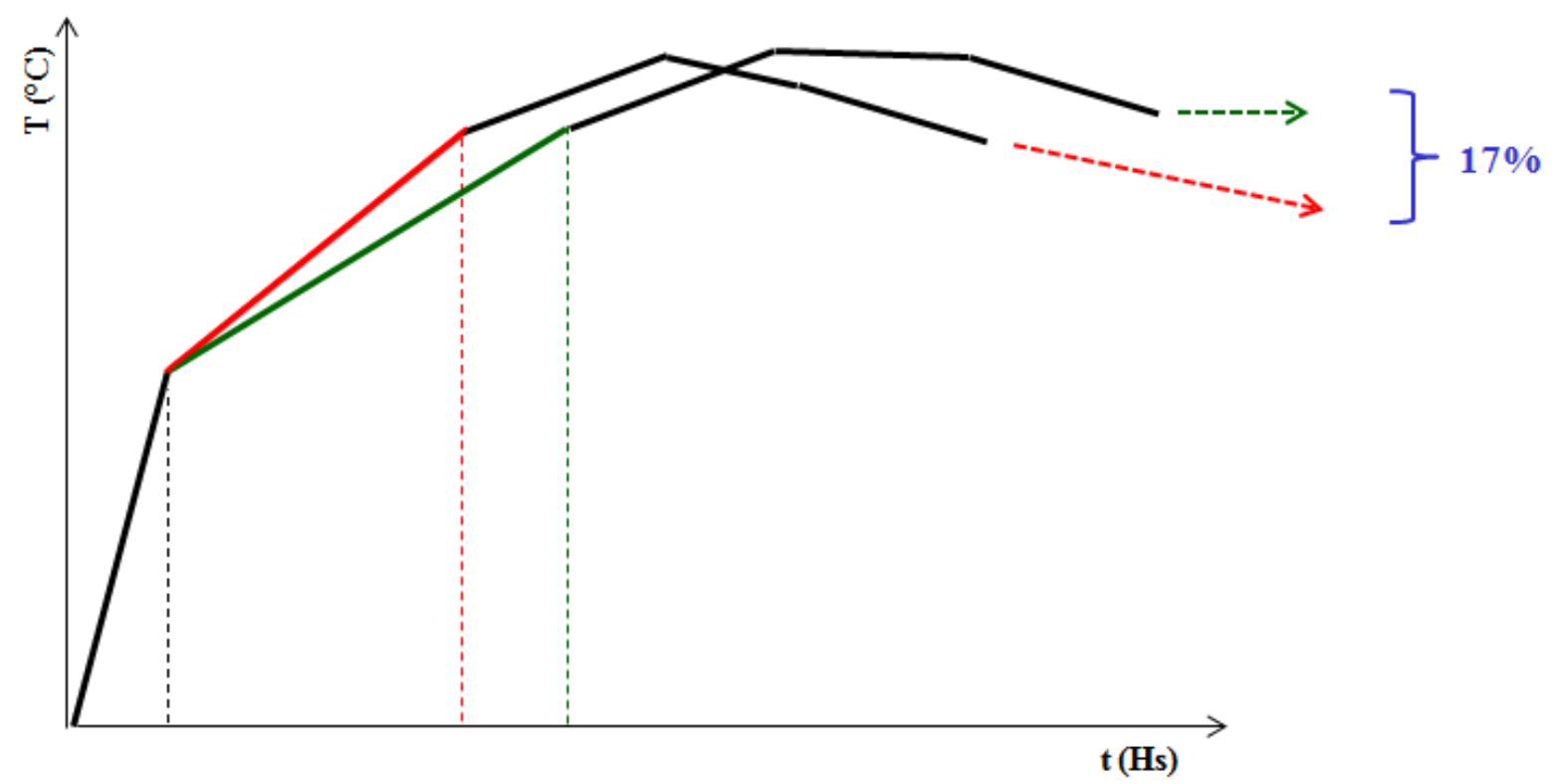

Figura 3. Ciclo térmico: condições antes e após a alteração da taxa de aquecimento.

* Contribuição técnica ao $69^{\circ}$ Congresso Anual da ABM - Internacional e ao 14ํㅡㄹ ENEMET - Encontro Nacional de Estudantes de Engenharia Metalúrgica, de Materiais e de Minas, 21 a 25 de julho de 2014, São Paulo, SP, Brasil. 


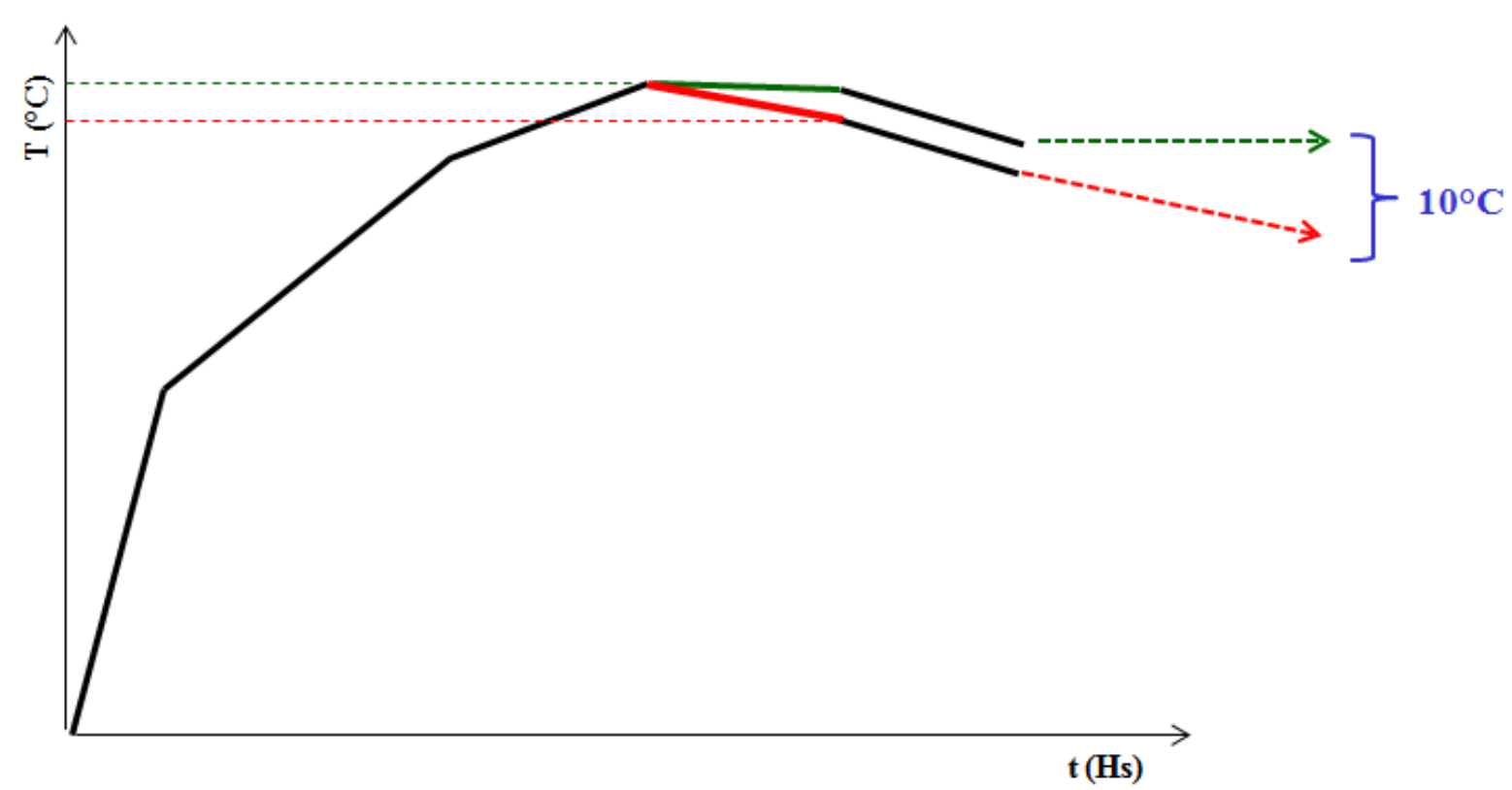

Figura 4. Ciclo térmico: condições antes e após a alteração da temperatura de encharque.

\subsection{Testes Realizados}

\subsubsection{Ensaio de Erichsen}

Os resultados obtidos de profundidade (em $\mathrm{mm}$ ) de conformação do ensaio de Erichsen (IE), materiais listados na Tabela 1, nas posições ao longo da largura conforme 2.2.1 é apresentado na Figura 5.

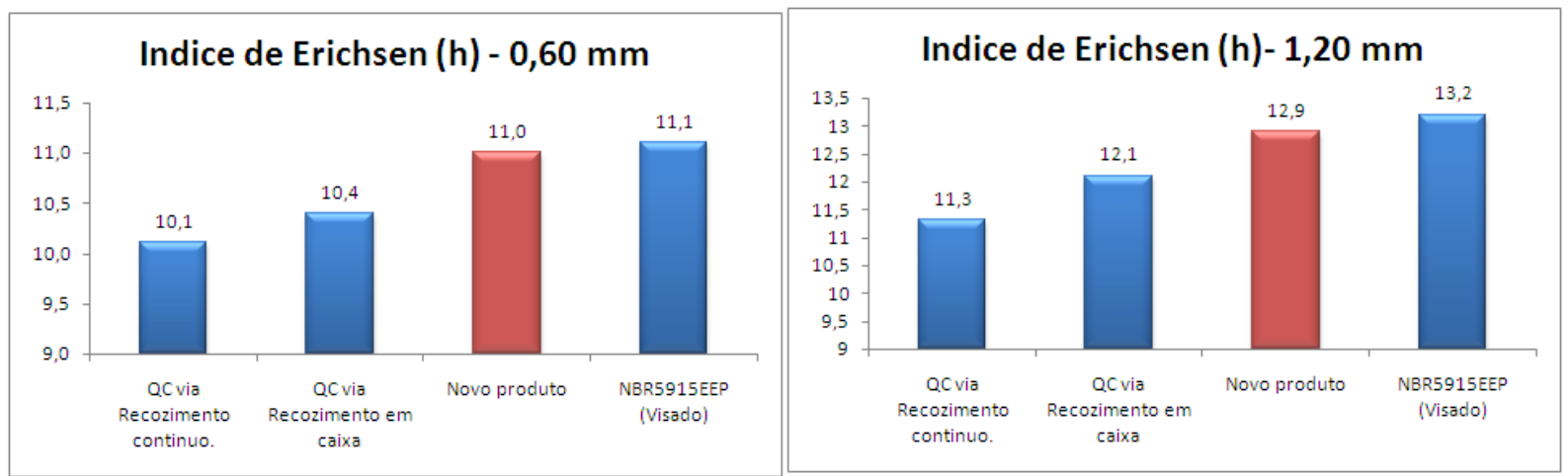

Figura 5. Resultados do ensaio de Erichsen. (a) espessura 0,60 mm; e (b) espessura 1,20 mm.

\subsubsection{Teste de campo}

Os materiais foram submetidos a testes de campo em clientes selecionados, aqui denominados A (Figura 6) e B (Figura 7), e os resultados foram bem sucedidos para a aplicação em carrinhos de mão utilizados na construção civil. Essa aplicação requer uma deformação significativa para o produto laminado a frio.

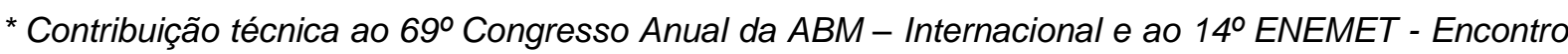
Nacional de Estudantes de Engenharia Metalúrgica, de Materiais e de Minas, 21 a 25 de julho de 2014, São Paulo, SP, Brasil.
} 

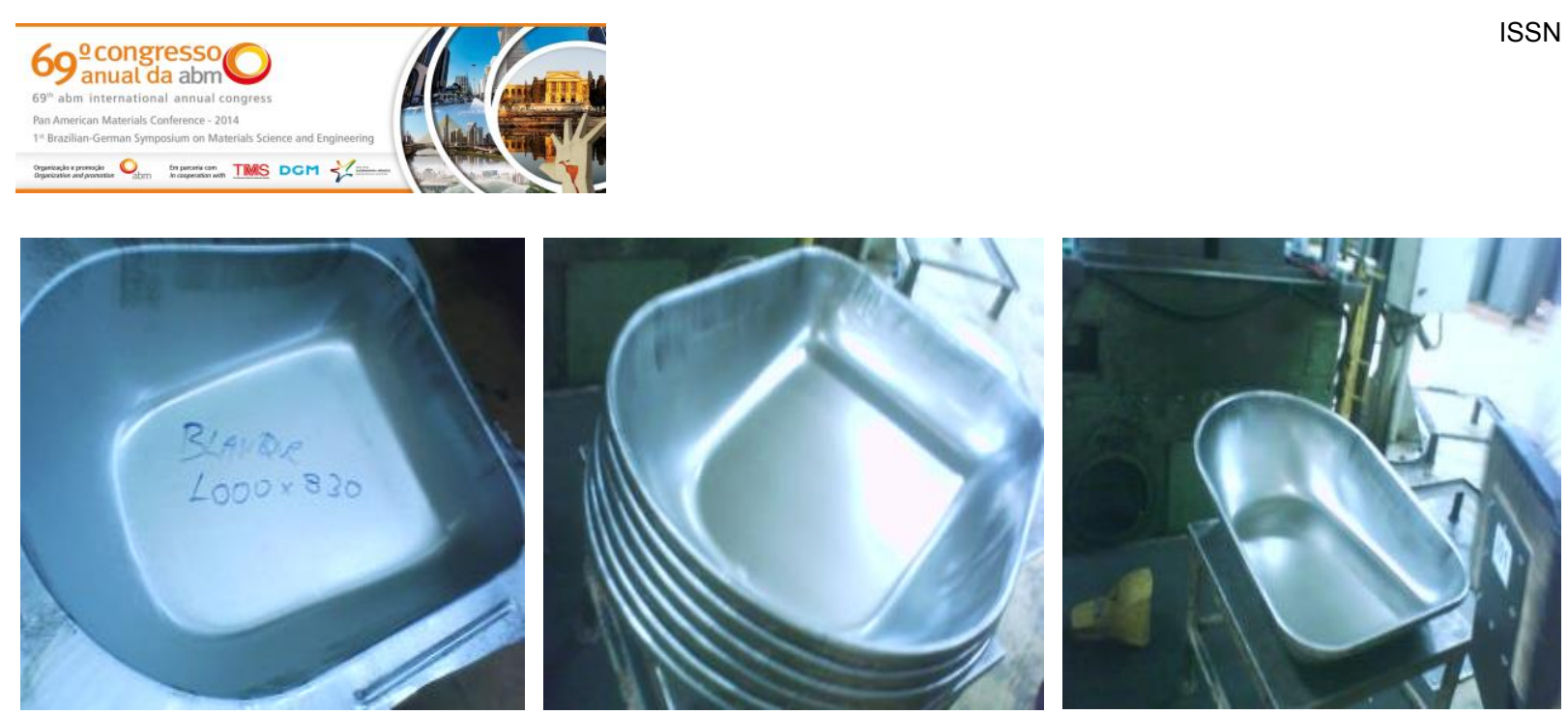

Figura 6. Teste em campo: Cliente "A" - Aplicação: carrinho de mão.
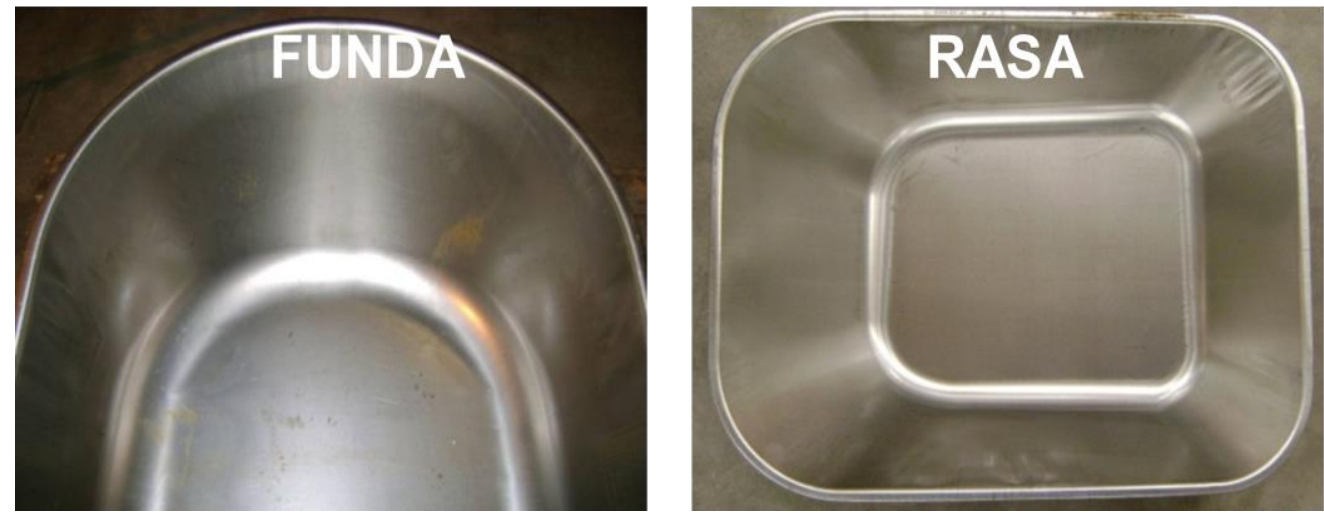

Figura 7. Teste em campo: Cliente B - Aplicação: carrinho de mão.

\section{DISCUSSÃO}

\subsection{Composição Química}

Para obtenção do produto final foi necessário avaliar o ponto de equilíbrio entre suas características mecânicas e seu custo de produção.

Não há dúvida de que a composição química é uma variável que contribui significativamente para a conformabilidade do produto final. No entanto, o custo mais baixo de produção de placa está relacionado com composições de produtos de qualidade comercial. Qualquer escolha de composição química diferente implicaria em automática elevação do custo total de produção, visto que o custo de placa contribui com parcela significativa, superior a $50 \%$, do custo final dos produtos laminados a frio.

Daí, a nova especificação teria como origem as placas com os menores custos possíveis de produção. Nesse contexto, resultados mais expressivos de propriedades mecânicas necessitariam de ajustes de condições de processamento.

\subsection{Condições de Processamento}

Destacamos dentre as etapas para a realização da nova especificação, anteriores ao recozimento em caixa (Figura 2 ), os processamentos nos laminadores de tiras a quente e de tiras a frio.

O estabelecimento de condições particulares, diferentes das correntemente padronizadas, de processamento nos equipamentos anteriores ao recozimento em caixa seria traduzido em elevação de custo seja por questões de impactos nas

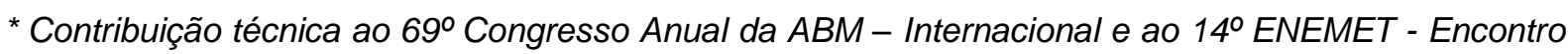
Nacional de Estudantes de Engenharia Metalúrgica, de Materiais e de Minas, 21 a 25 de julho de 2014, São Paulo, SP, Brasil.
} 


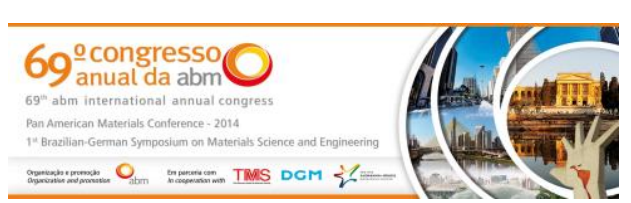

produtividades individuais dos equipamentos, tais como por desvios indesejados de produção. Daí, também para as condições de processamento foram estabelecidas condições similares às de produção atuais para os produtos de QC que têm produtividade global considerada boa.

\subsubsection{Laminação a quente}

No caso do laminador de tiras a quente, é a etapa do processamento onde ocorre a redução de espessura de uma placa de cerca de $250 \mathrm{~mm}$ para cerca de $3,50 \mathrm{~mm}$, dependendo da espessura final do produto acabado a frio, e o processo de resfriamento a partir do bobinamento que determina a morfologia da cementita, fundamental em um aço C-Mn, e o potencial para precipitação de AIN no processo de recozimento em caixa, este determinante para a produção da textura mais favorável para melhoria da conformabilidade do aço [5].

\subsubsection{Laminação a frio}

No caso do laminador de tiras a frio, uma redução de espessura importante se dá que é a força motriz para o processo de recristalização no momento do tratamento térmico [3].

\subsubsection{Processamento no forno de recozimento em caixa (FRCX)}

Em geral, o principal objetivo do recozimento em caixa é o de restituir ao material laminado a frio, encruado (também chamado full-hard), suas características de propriedades mecânicas compatíveis com aplicações que necessitem de ductilidade. O ciclo térmico (aquecimento, encharque e resfriamento) também pode ser projetado para conferir características requeridas que sejam específicas para alguma aplicação.

Com a composição química estabelecida em 2.1, foi necessário atuar no ciclo térmico de maneira a obter o melhor balanço possível com a conformabilidade. Para atingir esse objetivo o trabalho foi focado nas etapas de aquecimento e encharque.

\subsubsection{Etapa de aquecimento}

Inicia quando a temperatura no interior do forno (temperatura dos gases) atinge $400^{\circ} \mathrm{C}$ e termina com o inicio da etapa posterior, encharque.

A matéria-prima, bobina encruada, traz a herança das etapas de processamento anteriores microestrutura deformada da laminação a frio e elementos em solução, com potencial de precipitação, do resfriamento da laminação a quente, notadamente Al e N.

Durante o processo de recozimento a ocorrência de precipitação é controlada através de taxa de aquecimento. Daí, ser importante ajustar a etapa de aquecimento para potencializar seu efeito no resultado final da propriedade mecânica. A redução da taxa de aquecimento proporciona a condição cinética que permite a difusão para maximizar a formação de nitreto de alumínio (AIN) antes que se dê o início do encharque, ainda durante a recuperação. Essa precipitação ocorre em defeitos da estrutura laminada a frio e, assim a recristalização é retardada em planos de orientação desfavoráveis à característica de conformabilidade. Por outro lado, a nucleação não é significativamente afetada em planos de orientação que melhor potencializam a conformabilidade. O resultado são grãos com formatos mais alongados com morfologia conhecida como pancake grain ou em forma de panqueca [3].

\footnotetext{
* Contribuição técnica ao $69^{\circ}$ Congresso Anual da ABM - Internacional e ao 14ํㅡㄹ ENEMET - Encontro Nacional de Estudantes de Engenharia Metalúrgica, de Materiais e de Minas, 21 a 25 de julho de 2014, São Paulo, SP, Brasil.
} 


\subsubsection{Etapa de encharque}

A etapa de encharque segue a de aquecimento no ciclo térmico e é a responsável pelo crescimento de grão e, consequentemente, pelo aumento do tamanho médio do grão ferrítico.

Temperaturas de enchaque mais elevadas são favoráveis a menor dureza e maior ductilidade, fatores importantes para boa conformabilidade do aço.

Em um contexto de deformação a frio homogênea ao longo da bobina de aço, a elevação da temperatura de encharque também é benéfica para obter bobinas com maior homogeneidade de propriedades mecânicas entre suas posições de inicio, meio e final, ao longo de seu comprimento, devido a maior energia térmica disponibilizada no sistema.

Adicionando o resultado da etapa anterior de processamento (3.2.3.1), maior tamanho médio de grão ferrítico e maior homogeneidade microestrutural ao longo da bobina o resultado alcançado é de um produto final com melhor conformabilidade. Daí, a elevação de cerca de $10{ }^{\circ} \mathrm{C}$ foi estabelecido para o ciclo térmico da nova especificação.

A redução de $17 \%$ da taxa de aquecimento (Figura 3 ) e a elevação da temperatura de encharque (Figura 4) causaram os efeitos desejados nas propriedades mecânicas conforme Figuras 5 a 7 .

\subsection{Testes Realizados}

\subsubsection{Ensaio de Erichsen [8]}

Com os resultados obtidos dos ensaios dos materiais da Tabela 1, apresentados na Figura 5, é possível constatar que o valor médio de IE para a nova especificação de produto laminado a frio é maior do que os resultados obtidos para os produtos de especificações similares de QC tanto processados via recozimento em caixa, quanto via recozimento continuo.

Além disso, esses mesmos resultados confirmam que a nova especificação possui valor médio de IE semelhante ao de uma especificação EEP da NBR 5915 [7]. Portanto, as ações descritas em 4.2.3 atingiram o objetivo da boa conformabilidade desejada.

\subsubsection{Teste em campo}

Os locais de teste foram definidos pela aplicação de caçamba de carrinho de mão que representava um desafio para as caracterísiticas de elevado grau de conformabilidade exigido para um aço de especificação similar à QC.

Em ambos os clientes, A e B, foram obtidos desempenhos considerados excelentes, Figuras 8 e 9, quanto a seu grau de conformabilidade e interação com dos ferramentais utilizados. A aprovação foi obtida em ambos os casos mesmo quando foram testados modelos bastante distintos, Figura 9, com profundidades de caçamba diferentes.

No conjunto de resultados de condições de processamento, propriedades mecânicas e de desempenho no cliente final a especificação foi considerada bem sucedida nos objetivos pretendidos de disponibilizar um produto de baixo custo com propriedades mecânicas que the possibilitasse uma maior penetração de mercado em aplicações que utilizassem especificações similares à QC, mas que necessitassem de melhor desempenho em conformabilidade.

\footnotetext{
* Contribuição técnica ao $69^{\circ}$ Congresso Anual da ABM - Internacional e ao 14ํㅡㄹ ENEMET - Encontro Nacional de Estudantes de Engenharia Metalúrgica, de Materiais e de Minas, 21 a 25 de julho de 2014, São Paulo, SP, Brasil.
} 


\section{CONCLUSÃO}

Mediante ajustes do ciclo térmico à composição química, de características de QC, de baixo custo foi possível obter uma nova especificação de produto laminado a frio para atender ao segmento da Distribuição.

\section{Agradecimentos}

Os autores gostariam de agradecer a CSN por permitir a publicação do presente trabalho e a todas as pessoas engajadas na realização desse trabalho que não puderam figurar como co-autores (equipes de laboratórios, de produção, área técnica e desenvolvimento de produtos).

\section{REFERÊNCIAS}

1 Santos RM, Almeida KR, Alves RA, Silva CAS. Aumento da Produtividade dos Fornos de Recozimento em Caixa HPH da Companhia Siderúrgica Nacional. In: Seminário Interno. Volta Redonda: CSN; 2012.

2 Shewmon P. Diffusion in Solids. $2^{\underline{a}}$ ed. Pensylvannia: TMS; 1989.

3 Padilha AF, Siciliano Jr. F. Encruamento, Recristalização, Crescimento de Grão e Textura. 3를 ed. São Paulo: ABM; 2005.

4 Porter DA, Easterling KE. Phase Transformations in Metals and Alloys. $5^{\mathrm{a}}$ ed. Berkshire: Van Nostrand Reinhold (UK) Co. Ltd.; 1986.

5 Brito RM. Aspectos Microestruturais e Propriedades Mecânicas de Aços Baixo Carbono Acalmados ao Alumínio Submetidos a Recozimento Contínuo [Tese de Doutorado]. Rio de Janeiro: UFRJ; 1989.

6 Associação Brasileira De Normas Técnicas. ABNT NBR6658: Bobinas e chapas finas de aço-carbono para uso geral. Rio de Janeiro; 2009.

7 Associação Brasileira De Normas Técnicas. ABNT NBR5915-2: Chapas e bobinas de aço laminadas a frio: Parte 2: Aços para Estampagem. Rio de Janeiro; 2013.

8 DIN - Deutsche Normen. DIN EN ISO 20482: Metallic Materials Sheet And Strip Erichsen Cupping Test; 2003.

\footnotetext{
* Contribuição técnica ao $69^{\circ}$ Congresso Anual da ABM - Internacional e ao 14ํㅡㄹ ENEMET - Encontro Nacional de Estudantes de Engenharia Metalúrgica, de Materiais e de Minas, 21 a 25 de julho de 2014, São Paulo, SP, Brasil.
} 